\title{
Preparation and Performance of Polyimide with Noncoplanar Structure
}

\author{
Jing Zhang ${ }^{1}$, Xiaoqi Chen ${ }^{2}$, Haijun Zhou ${ }^{2}$, Xiaolei Zhang ${ }^{2}$ and Yantao Li ${ }^{2, *}$ \\ ${ }^{1}$ Chemical Institute, Heibei University of Technology, Tianjin 300130, China \\ ${ }^{2}$ Hebei Institute of Energy Source, Shijiazhuang 050081, China \\ *Corresponding author
}

\begin{abstract}
A series of polyimide was prepared based on 3,3',4,4'biphenyltetra carboxylic dianhydride (BPDA) with noncoplanar, 1,2,4,5-benzenetetracarboxylicanhydride (PMDA) and 4,4'diaminodiphenyl ether (ODA). The effect of the polymer structure and imidization temperature on the thermal stability and mechanical properties of polyimide was investigated. The results showed that the toughness of polyimide were effectively improved as the noncoplanar structure was introduced into polyimide molecular chain. The mechanical properties of polyimide reached the maximun at imidization temperature of $300{ }^{\circ} \mathrm{C}$. The tensile strength and elongation at break of polyimide were $51.84 \mathrm{MPa}$ and $13.63 \%$ respectively, and the high heat resistance was excellent.
\end{abstract}

Keywords-polyimide; imidization; thermal stability; mechanical property

\section{INTRODUCTION}

The high performance special engineering plastic can be made of polyimide by being moulded. Because of the excellent heat resistance and mechanical properties, the polyimide has been used widely, such as film, paint, fiber, foam plastics, engineering plastics and so on. At present, a lot of commercial polyimide, which was prepared from aromatic dianhydride and diamine with symmetric structure as the structure unit of polymer, are difficult to processing. But, the moulded product has the poor toughness and produced interal stress in using process. Therefore, the application of polyimide is restricted[15]. In this paper, a series of polyimide was prepared based on 3,3',4,4'-biphenyl-tetra carboxylic dianhydride(BPDA) with noncoplanar, 1,2,4,5-benzenetetracarboxylic anhydride (PMDA) and 4,4'-diaminodiphenyl ether(ODA). The symmetry and regularity of polyimide molecular strcuture were destroyed, as a certain proportional noncoplanar structure was introduced into molecular chain. the molecular force and crystallinity were reduced and the processability and toughness of product were improved. The effect of the imidization temperature on the thermal stablity and mechanical properties of polyimide was investigated.

\section{EXPERIMENTAL}

\section{A. Materials}

4,4'-diaminodiphenyl ether(ODA), 3,3',4,4'-iphenyltetra carboxylic dianhydride (BPDA),1,2,4,5Benzenetetracarboxylic anhydride(PMDA) were all industrial grade. N,N-Dimeth-
ylacetamide(DMAC), xylene and acetone were all analytical.

\section{B. Synthesis Process of Polyimide Moulding Powder}

A certain amount of ODA was dissolved in DMAC completely with stirring,then PMDA/BPDA (with the same molar ratio of ODA) were added into the solution. After 4 hours, xylene and catalyst were added into the solution, then the solution was heated to $156-160^{\circ} \mathrm{C}$, dehydrated for 3 hours and obtained with a yellow powder. The powder was filtered and washed with acetone, and then dried in vacuo. The imidization of powder was performed at $260^{\circ} \mathrm{C}, 280^{\circ} \mathrm{C}, 300^{\circ} \mathrm{C}$, $320^{\circ} \mathrm{C}$ and $340^{\circ} \mathrm{C}$ for the same time, respectively. Finally, the five kinds of powder with different imidization degree were obtained.

\section{Preparation of Polyimide}

Moulded the above five kinds of powder into $84 \mathrm{~mm} \times 66 \mathrm{~mm} \times 2 \mathrm{~mm}$ flake with pressure of $15 \mathrm{MPa}$ at $410^{\circ} \mathrm{C}$ $430^{\circ} \mathrm{C}$ for $10 \mathrm{~min}$. Then the polyimide flakes were cooled and demould.

\section{Characterization}

Infrared (IR) spectra were obtained with a FT-IR 100 spectrometer. Thermal stability, as measured by $5 \%$ or $10 \%$ weight loss of polyimide sample, was determined on a TGAQ50 analyzer from $50^{\circ} \mathrm{C}$ to $800^{\circ} \mathrm{C}$ at a heating rate of $20^{\circ} \mathrm{C} / \mathrm{min}$, under a flow of $\mathrm{N}_{2}$. The glass transition temperature $\left(\mathrm{T}_{\mathrm{g}}\right)$ was determined with a DMA-Q800 at a heating rate of $10^{\circ} \mathrm{C} / \mathrm{min}$ and frequency of $1 \mathrm{~Hz}$. The mechanical property of polyimide sample was measured according to the standard GB/T 10402006.

\section{RESULTS AND DISCUSSION}

\section{A. Infrared Analysis}

The polyamide acid was synthesized based on BPDA with noncoplanar, PMDA and ODA. Then the polyamide acid became into polyimide by the means of chemical and thermal imidization. The structure of polyimide was identified by IR spectrometer. The IR spectrum of polyimide was shown as in Fig.1.

The characteristic absorption peaks of $\mathrm{C}=\mathrm{O}$ in the imide group near $1780 \mathrm{~cm}^{-1}, 1720 \mathrm{~cm}^{-1}$ and $725 \mathrm{~cm}^{-1}$ appeared. The absorption of C-N at $1380 \mathrm{~cm}^{-1}$ appeared. The absorption of 
$\mathrm{N}-\mathrm{H}$ at $3500 \mathrm{~cm}^{-1}$ in polyamide acid disappeared. The results indicate the polyamide acid was successfully dehydrated to form polyimide.

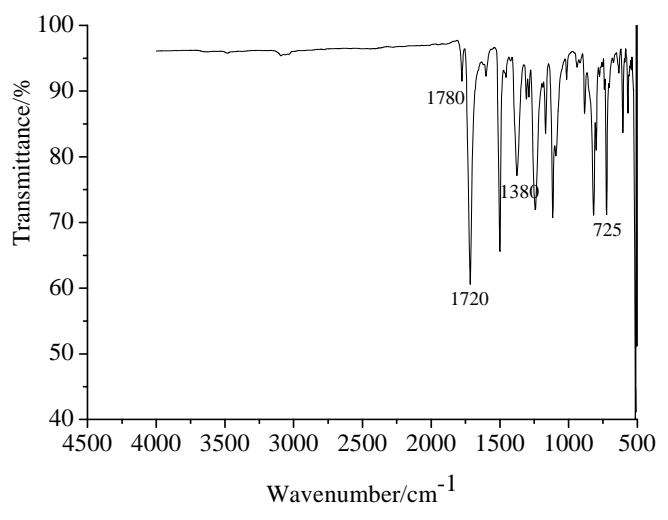

FIGURE I. INFRARED SPECTRUM OF POLYIMIDE.

\section{B. Imidization Degree}

The properties of polyimide are affected by imidization degree. If the imidization degree is low, there is water during the molding and will reduce the mechanical property of the polyimide product. The formula (1) is used to calculate the imidization rate [6,7].

$$
\text { imidizatiø rate }=\left(\mathrm{S}_{725} / \mathrm{S}_{1500}\right) \mathrm{t} /\left(\mathrm{S}_{725} / \mathrm{S}_{1500}\right)_{350}
$$

The $S_{725}$ and $S_{1500}$ represents the absorption peak area under the wavenumber of $725 \mathrm{~cm}^{-1}$ and $1500 \mathrm{~cm}^{-1}$, respectively. And the 350 and t represents the imidization temperature $350^{\circ} \mathrm{C}$ and $t^{\circ} \mathrm{C}$, respectively. The results of imidization rate were shown in the Fig.2.

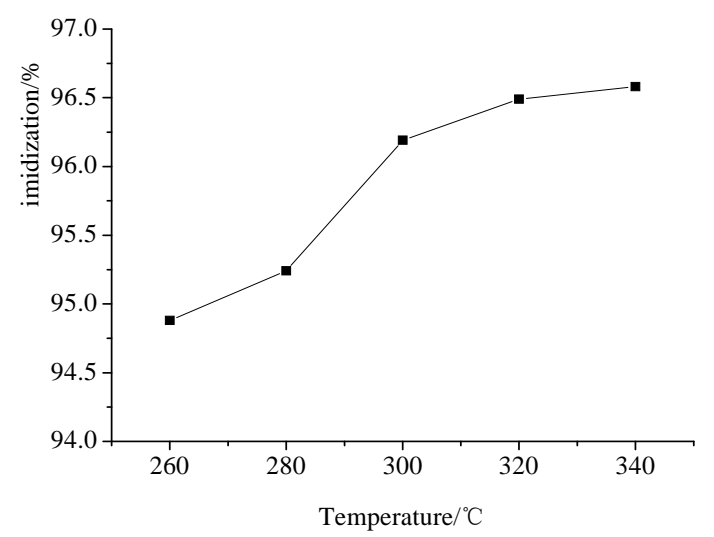

\section{FIGURE II. EFFECT OF IMIDIZATION TEMPERATURE ON THE IMIDIZATION RATE.}

The Fig.2 shows that the imidization rate reached $96.19 \%$, and $96.49 \%$ and $96.57 \%$ at $300{ }^{\circ} \mathrm{C}, 320{ }^{\circ} \mathrm{C}$ and $340{ }^{\circ} \mathrm{C}$, respectively. The imidization rate of polymer at $320^{\circ} \mathrm{C}$ and $340^{\circ} \mathrm{C}$ only increaseed by $0.3 \%$ and $0.38 \%$ than that of polymer at $300^{\circ} \mathrm{C}$, so the imidization temperature of $300{ }^{\circ} \mathrm{C}$ was chosen.

\section{Thermal Properties}

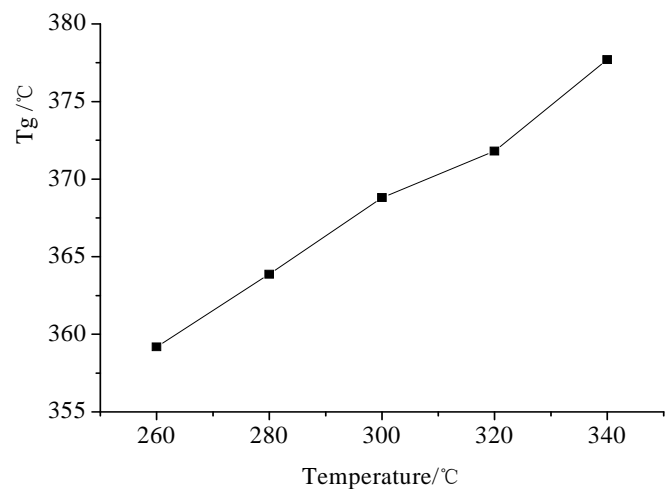

FIGURE III. EFFECT OF IMIDIZATION TEMPERATURE ON Tg.

In the Fig.3, the results show that glass translation temperature $\left(\mathrm{T}_{\mathrm{g}}\right)$ significantly increased with the increasing temperature. The $\mathrm{T}_{\mathrm{g}}$ of polyimide was up to $377^{\circ} \mathrm{C}$.

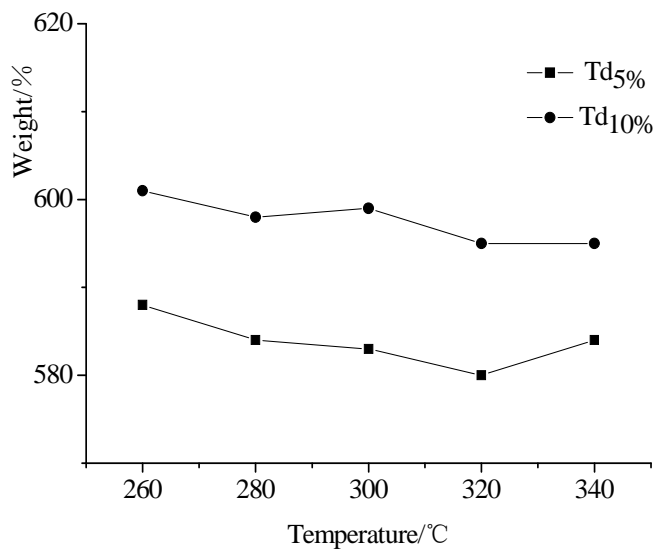

FIGURE IV. EFFECT OF IMIDIZATION TEMPERATURE ON Td.

The Fig. 4 shows the temperatures of $5 \%$ or $10 \%$ weight loss of polyimide at the different imidization temperatures. The result indicates that the thermal stability of polyimide decreased slightly with the increasing imidization temperat-ure. The $\mathrm{Td} 5 \%$ and $\mathrm{Td} 10 \%$ of polyimide at imidization temperature of $300^{\circ} \mathrm{C}$ were $583^{\circ} \mathrm{C}$ and $599^{\circ} \mathrm{C}$, respectively, and were of excellent heat-resisting performance.

\section{Mechanical Properties}

The Fig. 5 shows that the tensile strength and elongation at break of polyimide increased as the imidization temperat-ure rose.At the imidization temperature of $300{ }^{\circ} \mathrm{C}$, the tensile strength and elongation at break were 51.84 MPa and 13.6

$\%$, respectively. Though the tensile strength was slightly lower, 
the elongation at break is higher than the commercial polyimide. The results indicate that the toughness of polyimide was effiectively improved as the noncoplanar structure was introduced into the polyimide molecular chain.

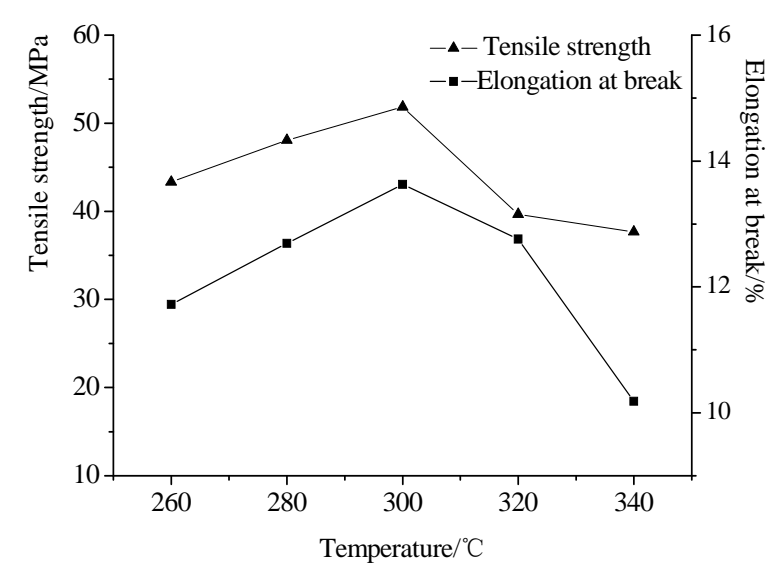

FIGURE V. EFFECT OF IMIDIZATION TEMPERATURE ON MECHANICAL PROPERTY OF POLYIMIDE.

\section{CONCLUSIONS}

(1) the toughness of polyimide is effectively improved as the noncoplanar structure is introduced into the polyimide molecular chain.

(2) It is approprite that the imidization temperature is chosen at $300^{\circ} \mathrm{C}$, at which the tensile strength and elongation at break are $51.84 \mathrm{MPa}$ and $13.63 \%$ respectively, and reached the maximum value.

\section{REFERENCE}

[1] Kai Wang, Shengqiang Gao, Maosheng Zhan et al. Development of Thermoplastic Polyimide. Polymer Bulletin, 2005, (3):25-32.

[2] Yunliang Wang, Xiaohui Yu, Lina Wang et al.Synthesis and Characterization of Polypyromelliticimide Polyimide Molding Powders. Chemical Journal of Chinese Universities, 2012,33(10) :2356-2360.

[3] Mengxian Ding, Tianbai He. New material of Polyimide. Beijing: science press. 1998.

[4] Y. Imai, R. Yokota. Polyimides Fundamental and Application. Tokyo: NTS Inc. Press, 2002:173-183.

[5] Kai Wang, Shengqiang Gao, Maosheng Zhan et al. Development of Melt - processable Thermoplastic Polyimides. Aerospace Materials \& Technology, 2004(3):5-11.

[6] Sheng Zhou, Youbing Fan, Yatao Li. Study on the imdization of polypyrom- ellticimide insulation varnish and its effect on the properties. Insulating Material, 2003, (6):34-36.

[7] Yan Zhai. Controllable Aggregation Structure Preparation and Films Properties Study for Polyimide based on PMDA-ODA. Sichuan University : College of Polymer Science and Engineering in Sichuan University, 2007, 53. 